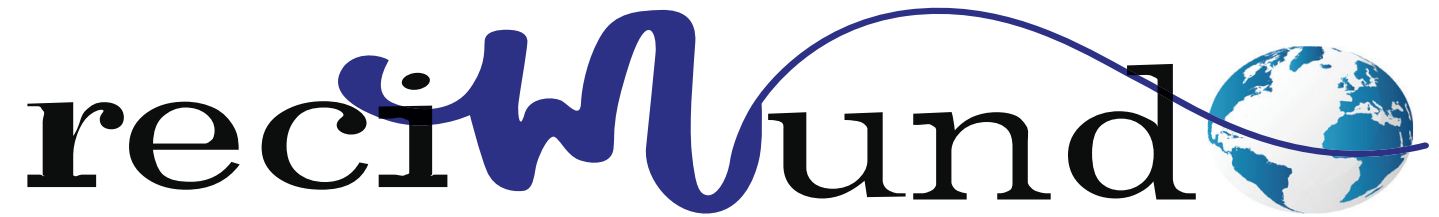

Revista Científica Mundo de la Investigación y el Conocimiento

DOI: 10.26820/recimundo/4.(1).enero.2020.183-191

URL: http://recimundo.com/index.php/es/article/view/733

EDITORIAL: Saberes del Conocimiento

REVISTA: RECIMUNDO

ISSN: 2588-073X

TIPO DE INVESTIGACIÓN: Artículo de Revisión

CÓdIGO UNESCO: 3202 Epidemiología

PAGINAS: 183-191

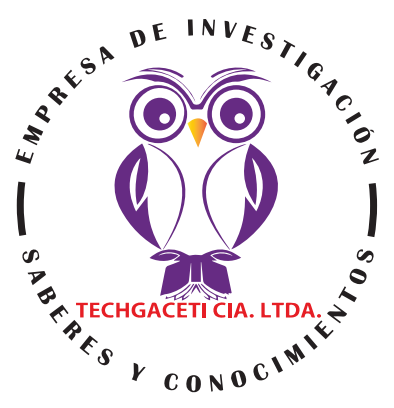

\title{
Morbimortalidad del dengue grave
}

\section{Morbimortality of severe dengue}

Morbimortalidade da dengue grave

Katiuska Katherine Contreras Cano ${ }^{\text {; }}$ Karla Geoconda Boada Rodríguez2; Jonathan Eduardo Jarrin Torres;

Cynthia Gabriela Albán Espinoza ${ }^{4}$

\section{RECIBIDO: 18/09/2019 ACEPTADO: 29/10/2019 PUBLICADO: 31/01/2020}

1. Médico; Investigador Independiente; Guayaquil, Ecuador; katherincontreras5728@hotmail.com; (D) https://orcid.org/0000-0003-4283-2529

2. Médico; Investigador Independiente; Guayaquil, Ecuador; karlita0317@hotmail.es; (D) https://orcid.org/00000002-4791-7946

3. Máster Universitario en Dirección y Gestión de Unidades de Enfermería; Licenciado en Enfermería; Investigador Independiente; Guayaquil, Ecuador, Ecuador; Joejarrin92@hotmail.com; (D) https://orcid.org/0000-00028617-3206

4. Médico Cirujano; Investigador Independiente; Guayaquil, Ecuador; gabysalban@gmail.com; (D) https://orcid. org/0000-0002-4952-9592

CORRESPONDENCIA

Katiuska Katherine Contreras Cano

katherincontreras5728@hotmail.com

Guayaquil, Ecuador 


\section{RESUMEN}

El Dengue es una enfermedad infecciosa, producida por un arbovirus cuyo único reservorio es el hombre. El virus utiliza como vector biológico al mosquito Aedes aegypti o al mosquito Aedes albopictus. La sintomatología se presenta como un cuadro febril denominado dengue clásico, que se caracteriza por fiebre alta de presentación aguda, de duración limitada (2 a 7 días), con intenso malestar general, acompañado de erupción cutánea. Las formas graves, dengue hemorrágico y síndrome de choque por dengue, ocurren mediante un mecanismo denominado reforzamiento inmunológico, propiciado usualmente por infecciones secuenciales por serotipos heterólogos. En estas variantes clínicas, se manifiestan las hemorragias, el aumento de la permeabilidad vascular, la serositis, la hepatomegalia o el fallo circulatorio y, sin restitución hídrica parenteral, las personas afectadas pueden fallecer rápidamente. El factor de riesgo principal de sufrir dengue hemorrágico es tener una segunda infección con un serotipo diferente del que causó la infección primaria. Los anticuerpos de la clase IgM contra el virus del dengue se pueden detectar en más de 95\% de los casos a partir del quinto día de la enfermedad. Según datos de la Organización Mundial de la Salud, Brasil ocupa el primer puesto entre los treinta países del mundo con mayor número de casos notificados de dengue. Otros países donde el dengue es endémico son Venezuela, Colombia, Bolivia, Perú, Paraguay, Ecuador y Argentina. Las medidas de prevención y control como el uso de mosquiteros, eliminación adecuada de desechos y criaderos potenciales, la aplicación de antilarvarios e insecticidas, así como la educación para la salud dirigida a población general y en particular a la población en riesgo. Se usó una metodología descriptiva, con un enfoque documental, es decir, revisar fuentes disponibles en la red, con contenido oportuno y relevante para dar respuesta a lo tratado en el presente artículo.

Palabras clave: Dengue, Morbilidad, Arbovirus, Serotipos, Infección, Dengue Hemorrágico.

\section{ABSTRACT}

Dengue is an infectious disease, produced by an arbovirus whose only reservoir is man. The virus uses the Aedes aegypti mosquito or the Aedes albopictus mosquito as a biological vector. The symptomatology is presented as a febrile condition called classic dengue, which is characterized by acute fever of acute presentation, of limited duration (2 to 7 days), with intense general malaise, accompanied by skin rash. Severe forms, hemorrhagic dengue and dengue shock syndrome, occur through a mechanism called immunological reinforcement, usually caused by sequential infections by heterologous serotypes. In these clinical variants, hemorrhages, increased vascular permeability, serositis, hepatomegaly or circulatory failure are manifested and, without parenteral water restitution, affected people can die quickly. The main risk factor for hemorrhagic dengue is having a second infection with a different serotype than the one that caused the primary infection. IgM class antibodies against dengue virus can be detected in more than 95\% of cases from the fifth day of the disease. According to data from the World Health Organization, Brazil ranks first among the thirty countries in the world with the highest number of reported dengue cases. Other countries where dengue is endemic are Venezuela, Colombia, Bolivia, Peru, Paraguay, Ecuador and Argentina. Prevention and control measures such as the use of mosquito nets, adequate disposal of waste and potential hatcheries, the application of antilarvaries and insecticides, as well as health education aimed at the general population and in particular the population at risk. A descriptive methodology was used, with a documentary approach, that is, to review sources available on the network, with timely and relevant content to respond to what is discussed in this article.

Keywords: Dengue, Morbidity, Arbovirus, Serotypes, Infection, Hemorrhagic Dengue.

\section{RESUMO}

A dengue é uma doença infecciosa, produzida por um arbovírus cujo único reservatório é o homem. O vírus usa o mosquito Aedes aegypti ou o mosquito Aedes albopictus como vetor biológico. A sintomatologia é apresentada como uma condição febril denominada dengue clássica, caracterizada por febre aguda de apresentação aguda, duração limitada (2 a 7 dias), com intenso mal-estar geral, acompanhado de erupção cutânea. Formas graves, dengue hemorrágica e síndrome do choque da dengue, ocorrem através de um mecanismo chamado reforço imunológico, geralmente causado por infecções seqüenciais por sorotipos heterólogos. Nessas variantes clínicas, hemorragias, aumento da permeabilidade vascular, serosite, hepatomegalia ou insuficiência circulatória são manifestadas e, sem restituição parenteral da água, as pessoas afetadas podem morrer rapidamente. O principal fator de risco para a dengue hemorrágica é ter uma segunda infecção com um sorotipo diferente daquele que causou a infecção primária. Os anticorpos da classe IgM contra o vírus da dengue podem ser detectados em mais de 95\% dos casos a partir do quinto dia da doença. Segundo dados da Organização Mundial da Saúde, o Brasil ocupa o primeiro lugar entre os trinta países do mundo com o maior número de casos relatados de dengue. Outros países onde a dengue é endêmica são Venezuela, Colômbia, Bolívia, Peru, Paraguai, Equador e Argentina. Medidas de prevenção e controle, como o uso de redes mosquiteiras, descarte adequado de resíduos e incubatórios em potencial, aplicação de antilarvários e inseticidas, bem como educação em saúde voltada para a população em geral e, em particular, a população em risco. Utilizou-se uma metodologia descritiva, com abordagem documental, ou seja, para revisar as fontes disponíveis na rede, com conteúdo oportuno e relevante para responder ao que é discutido neste artigo.

Palavras-chave: Dengue, Morbidade, Arbovírus, Sorotipos, Infecção, Dengue Hemorrágica. 


\section{Introducción}

La elaboración de un diagnóstico sobre la situación sanitaria derivada del dengue es crucial por razones de salud pública en todo el mundo, ya que más de 2500 millones de personas es decir, $40 \%$ de la población mundial viven en zonas donde las probabilidades de contraer dengue son elevadas. La Organización Mundial de la Salud (OMS) ha determinado que el dengue es endémi$\mathrm{co}$, que existe circulación del virus durante todo el año en América, el sudeste asiático, el Pacífico occidental, África y el Mediterráneo oriental (Heredia, 2019).

La Región de las Américas se caracteriza por presentar un alto grado de urbanización, a tal punto que alberga cinco de las treinta megalópolis del planeta: dos están en Brasil (posición 4 y 19) y las restantes, en México, Argentina y Perú (posiciones 6, 13 y 30 , respectivamente). Considerando que el mosquito se ha adaptado a los entornos urbanos, el riesgo de contraer la enfermedad se potencia (Restrepo-Arboleda, 2004).

Las grandes urbes son el centro de las actividades productivas y gubernamentales donde el debilitamiento de los sistemas de salud pública como resultado de las privatizaciones desmedidas y la falta de programas sostenibles han favorecido la propagación del dengue al sur del Río Bravo hasta convertirse en una enfermedad endémica en toda la región, salvo en Chile y Uruguay. En lugares de escasa planificación sanitaria, el aumento del tránsito de personas y mercancías que conlleva la globalización favorece la propagación del vector en todo el planeta.

\section{Metodología}

Esta investigación está dirigida al estudio del tema "Morbimortalidad del Dengue Grave". Para realizarlo se usó una metodología descriptiva, con un enfoque documental, es decir, revisar fuentes disponibles en la red, como google académico, con contenido oportuno y relevante desde el punto de vis- ta científico para dar respuesta a lo tratado en el presente artículo y que sirvan de inspiración para realizar otros proyectos. Las mismas pueden ser estudiadas al final, en la bibliografía.

\section{Resultados}

Es una enfermedad con amplia gama y curso clínico impredecible. En términos generales es aceptada la clasificación en tres etapas o fases por las cuales cursa el dengue: fase febril (2-7 días), fase crítica y fase de recuperación. Una segunda clasificación derivada, establece la presencia o ausencia de signos de alarma. Estos signos permiten identificar precozmente la extravasación de líquidos y la posibilidad inminente de estado de choque. Además, existe evidencia de que las alteraciones bioquímicas puedan ser resumidas en la siguiente Tabla. 
Tabla 1. Signos de alarma del Dengue

\begin{tabular}{l}
\hline Dengue con signos de alarma \\
- Dolor abdominal intenso y continúo. \\
- Vómitos persistentes. \\
- Edema-serositis: detectado por clínica, \\
laboratorio (hipoalbuminemia) o imagen \\
(ecografía, Rx de tórax). \\
- Sangrado de mucosas. \\
- Letargia, somnolencia. \\
- Hepatomegalia (>2cm). \\
- Disminución de la diuresis. \\
- Disminución repentina de la temperatural \\
hipotermia. \\
- Incremento en el hematocrito con rápido \\
descenso de plaquetas. \\
\hline
\end{tabular}

Fuente: (Londoño-Ocampo, 2014)

Las formas graves, dengue hemorrágico y síndrome de choque por dengue, ocurren mediante un mecanismo denominado reforzamiento inmunológico, propiciado usualmente por infecciones secuenciales por serotipos heterólogos. En estas variantes clínicas, se manifiestan las hemorragias, el aumento de la permeabilidad vascular, la serositis, la hepatomegalia o el fallo circulatorio y, sin restitución hídrica parenteral, las personas afectadas pueden fallecer rápidamente.

Existe otra clasificación binaria de importancia: dengue y dengue grave. Los criterios de gravedad para dengue, incluyen la presencia de uno o más de estos tres criterios: extravasación marcada de plasma, expresada en el estado de choque hipovolémico y/o dificultad respiratoria (a causa de la acumulación de líquido). En segundo lugar, compromiso de órgano: encefalitis, miocarditis, hepatitis grave por dengue (transami- nasas superiores a 1000 unidades) en tercer lugar, hemorragias abundantes según criterio médico.

\section{Biología del Aedes Aegypti}

Los cambios climáticos observados de los últimos años, han impactado en la modificación de los nichos ecológicos que anidan muchas de las enfermedades infecciosas. Las enfermedades transmitidas por vectores y las zoonosis no son una excepción, aumentando su re emergencia y diseminación. En el caso del dengue, este mosquito fue introducido en América, siendo una especie diseminada por el hombre por medio del transporte en barcos, aviones y transportes terrestres.

Sus hábitos son antropófilos y domésticos, con radicación de criaderos en la vivienda. Los depósitos de agua ubicados en objetos o construcciones, como 
neumáticos, baterías viejas, recipientes de todo tipo, le sirven a $A$. aegypti para establecer sus criaderos en agua limpia, con bajo tenor orgánico, mediante la puesta de huevos en la inter fase agua-aire. Si se dan las óptimas condiciones de humedad y temperatura, el embrión evoluciona en un lapso de 2-3 días. Las larvas que emergen inician un ciclo de cuatro estados larvarios, creciendo a lo largo de tres mudas desde un largo de 1 $\mathrm{mm}$ a los 6 o $7 \mathrm{~mm}$ finales (Venegas-Rivera, 2012).

Estas larvas se alimentan con el fitoplancton de los recipientes que habitan. Su desarrollo se completa en condiciones favorables de nutrición y con temperaturas de 25 a $29^{\circ} \mathrm{C}$, en 5 a días. Son incapaces de resistir temperaturas inferiores a $10^{\circ} \mathrm{C}$ o superiores a $44^{\circ} \mathrm{C}$. El ciclo completo de A.aegypti, de huevo a adulto, se define en 10 días (Duane-Gubler, 1992).

El adulto emergente es un mosquito de color negro, con diseños blanco-plateados formados por escamas claras que se disponen simulando la forma de una "lira", en el dorso del tórax, y mostrando un anillado característico a nivel de tarsos, tibia y fémures de las patas. Las hembras son hematófagas, debido a que utilizan las proteínas de la sangre extraída para favorecer el crecimiento de sus huevos, siendo el vehículo de propagación del virus, teniendo hábitos de alimentación diurnos, en cercanía a los domicilios humanos con gran afinidad a la alimentación sobre el hombre. Los machos en tanto, se alimentan de néctar.

\section{Patogenia}

El factor de riesgo principal de sufrir dengue hemorrágico es tener una segunda infección con un serotipo diferente del que causó la infección primaria. Otros factores de riesgo es tener menos de 15 años de edad, ser de la raza blanca y sufrir de enfermedades crónicas como el asma, la diabetes y la anemia de células falciformes. En el cur- so de la infección primaria, el virus penetra en la célula diana mediante su unión a un receptor celular y se generan anticuerpos neutralizantes capaces de proteger contra la reinfección con ese mismo serotipo y durante solo 2 a 3 meses contra los otros serotipos.

Durante una infección secundaria con un serotipo heterológica se forman complejos virus-anticuerpos que se introducen en las células del sistema fagocítico mononuclear (monocitos y macrófagos) gracias a la unión del fragmento constante de la inmunoglobulina que forma parte del inmuno complejo a los receptores celulares del tipo gamma. Como consecuencia se infecta un mayor número de células y se favorece la diseminación viral. Este fenómeno se conoce como amplificación dependiente de anticuerpos (Restrepo-Arboleda, 2004).

La activación de los linfocitos T y la producción de citocinas son también factores importantes en la patogenia del dengue hemorrágico. Después de una infección primaria se producen clones de células $T$ CD4+ y CD8+ efectoras y con memoria que son específicas para el serotipo infectante, aunque capaces de reconocer los restantes serotipos. En el desarrollo de una segunda infección se activan los clones con memoria frente al nuevo serotipo y así se desencadena la respuesta inmunitaria. En los casos de $\mathrm{DH}$ se exacerba la activación y liberación de citocinas, lo que se relaciona con la mayor gravedad del cuadro clínico.

También se ha demostrado que en los pacientes con dengue hemorrágico se activa el sistema del complemento y en los casos graves se pueden detectar concentraciones elevadas de las proteínas C3 y C1q. Se plantea que los complejos virus-anticuerpos circulantes podrían ser los que activan la reacción en cascada del complemento. El dengue hemorrágico se acompañe de reacciones auto inmunitario. Estos anticuerpos pueden desempeñar un papel importante en el mecanismo patogénico durante 
la infección secundaria.

Otro factor a considerar el complejo mecanismo patogénico del dengue hemorrágico es la virulencia de la cepa infectante. En este sentido se ha reconocido la asociación de algunos genotipos, como los serotipos Den 2 y Den 3 de origen asiático, con casos y epidemias de dengue hemorrágico. Los enfermos con dengue presentan una menor carga viral que los enfermos con dengue hemorrágico. El avance de la ciencia ha demostrado la presencia de componentes determinantes de virulencia en la proteína $E$ y en el extremo 3ro del genoma viral.

\section{Diagnóstico}

El virus puede detectarse en la sangre desde 2 o 3 días antes del comienzo de la fiebre hasta 4 o 5 días después de su desaparición. Los anticuerpos de la clase IgM contra el virus del dengue se pueden detectar en más de 95\% de los casos a partir del quinto día de la enfermedad. En la infección primaria, los anticuerpos de la clase IgG se comienzan a detectar entre el $7 \mathrm{mo}$ y el $10 \mathrm{mo}$ día de fiebre, mientras que en la infección secundaria se observa un incremento muy temprano de los anticuerpos IgG con títulos muy elevados a partir del segundo día de fiebre. En algunos casos de infección secundaria no se detectan anticuerpos IgM (Guzmán-García, 2006).

La detección de anticuerpos IgM contra el dengue es suficiente para considerar el caso como probable y se debe notificar a las autoridades de salud. Cuando se confirma la seroconversión mediante la detección de anticuerpos IgG o cuando su valor aumenta cuatro veces o más, se considera confirmado el caso de dengue. Los antecedentes clínicos y epidemiológicos que acompañan al paciente son muy importantes para el diagnóstico final.

Los métodos directos permiten un diagnóstico de certeza, los indirectos dependen de la respuesta inmune del huésped y se aplican para confirmación después de los primeros días de la presentación de la enfermedad. Los métodos de diagnóstico directo empleados para dengue son: cultivo, RT-PCR (PCR en tiempo real), y ELISA para detección del antígeno NS1. Los métodos indirectos incluyen ELISA-IgM, en el que hay reacción cruzada con otros flavivirus; MAC-ELISA, y neutralización por reducción de placas (PRNT), que diferencia los 4 serotipos DENV y otros flavivirus (Kantor, 2016).

Estudios recientes demuestran que los títulos de anticuerpos de las clases IgA e IgE se elevan durante la infección aguda por dengue, se desconoce el papel que desempeñan estos anticuerpos desde el punto de vista de la respuesta inmunitaria y la patogenia de la enfermedad. Se debe evaluar su valor diagnóstico y posible utilidad para pronosticar la evolución a formas graves de la enfermedad (Martínez-Díaz, Septiembre 2006).

Otros métodos de diagnóstico confirmatorio lograron identificar el genotipo de la cepa infectante se basan en la amplificación y detección de secuencias específicas del genoma viral mediante la reacción en cadena de la polimerasa (RCP) en sus diferentes variantes (ya sea anidada o en tiempo real). Para ello se utilizan principalmente segmentos del gen que codifica la proteína $\mathrm{E}$ o de alguno de los genes que codifican algunas proteínas no estructurales.

\section{Dengue en Latinoamérica}

Según datos de la Organización Mundial de la Salud, Brasil ocupa el primer puesto entre los treinta países del mundo con mayor número de casos notificados de dengue. Otros países donde el dengue es endémico son Venezuela, Colombia, Bolivia, Perú, Paraguay, Ecuador y Argentina, que ocupan los puestos 5, 8, 13, 18, 19, 27 y 30, respectivamente (Masciadri, Enero 2019).

En términos comparativos, si bien Brasil era el único estado miembro donde se habían registrado casos de dengue (63,6 por cien mil), los problemas de salud vinculados con 
la endemia del dengue también existían en Bolivia (1392,9 por cien mil), Colombia (43,3 por cien mil), Venezuela (32,3 por cien mil), Perú (3,2 por cien mil) y Ecuador (0,9 por cien mil) (Masciadri, Enero 2019). Las tasas más elevadas de morbilidad por dengue en la región provenían de Paraguay (1034,1 por cien mil), Brasil (793,4 por cien mil), Bolivia (275,4 por cien mil), Ecuador (263,2 por cien mil), Colombia (200 por cien mil), Venezuela (174,1 por cien mil) y Perú (114,2 por cien mil) (Masciadri, Enero 2019).

En otros países, la incidencia seguía siendo baja o moderada, como en Guyana (50,6 por cien mil), Argentina (11 por cien mil) y Surinam (2,8 por cien mil). Por último, como ya se ha comentado, Uruguay $(0,4$ por cien mil) y Chile (0,2 por cien mil) mostraron ser los únicos dos países de la región donde el dengue no era ni es endémico. Cabe destacar que las tasas provinciales de dengue, al ser un indicador agregado, invisibilizan la situación de las zonas fronterizas, donde la exposición al riesgo de contagio es mayor a causa de la circulación turística y comercial.

En la más reciente nota epidemiológica de la Organización Panamericana de la Salud sobre el dengue, publicada el 22 de febrero del 2019, consta que el año pasado se notificaron 560586 casos de dengue en la región; 3535 diagnósticos fueron graves y 336 defunciones. Las primeras seis semanas del 2019 se registraron 100000 casos de dengue. De ellos, 632 casos graves y 28 defunciones. En Ecuador el año 2018 cerró con 3.094 casos por dengue. Lo informó en febrero del 2019 el Ministerio de Salud, la cifra del año anterior es inferior a la del 2016 y 2017. En esos años se presentaron 14.159 y 11.387 casos, respectivamente. En el 2018, la provincia con el mayor número de casos de dengue fue Manabí, con 880. Le siguen Guayas, con 525, y El Oro, con 301. En octavo lugar está Pichincha con 81 diagnósticos (Heredia, 2019).

La Organización Panamericana de la Salud recomienda a los países que intensifiquen la vigilancia de la enfermedad, así como las medidas de control de vectores para reducir la población de mosquitos que pueden transmitir. A estas acciones deben sumarse la educación continua a la población, el involucramiento de la comunidad y la capacitación y cuidado a los profesionales de salud.

En la actualidad, la situación en estos países es compleja, no obstante existen las bases para frenar la tendencia creciente del dengue y revertirla. La mayoría de los países cuentan con programas de prevención y control con diferentes grados de desarrollo, existe una red de laboratorios con capacidad diagnóstica y se cuenta con varios centros colaboradores de la OPS, cuya gestión puede tener un mayor impacto en el enfrentamiento del dengue y de otros agentes patógenos, mediante un trabajo coordinado (Periago-Guzmán, 2007).

El actual fortalecimiento de los sistemas de salud pública en varios de los países de la Región y la creciente voluntad política son factores decisivos para lograr la integración, la intersectorialidad y la prioridad necesarias para enfrentar al dengue. Las condiciones creadas y la estrategia establecida pueden y deben permitir alcanzar la meta de detener la expansión creciente del dengue en esta zona y paulatinamente comenzar a reducir la morbilidad, la mortalidad y el impacto social y económico de la enfermedad en las Américas.

\section{Posibilidades de prevención}

La falta de medidas eficaces de lucha contra los mosquitos y la creciente urbanización en muchas zonas tropicales permiten que grandes poblaciones de mosquitos vectores vivan en estrecho contacto con la población humana. Se crean así condiciones ideales para la diseminación de enfermedades transmitidas por mosquitos. Además, la mayor frecuencia de viajes aéreos proporciona un mecanismo ideal para el transporte de virus del dengue entre los centros de población de las zonas tropicales. Como re-

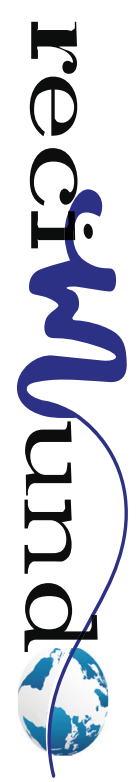


sultado, se introducen repetidamente virus del dengue en zonas muy propicias para la transmisión de la enfermedad, lo cual parece asegurar que se producirán epidemias cada vez más frecuentes de dengue y tal vez de dengue hemorrágico (Duane-Gubler, 1992).

Las medidas de prevención y control como el uso de mosquiteros, eliminación adecuada de desechos y criaderos potenciales, la aplicación de antilarvarios e insecticidas, así como la educación para la salud dirigida a población general y en particular a la población en riesgo, son fundamentales para el disminuir y prevenir esta enfermedad.

La voluntad política, la intersectorialidad, la participación de la comunidad, en otras palabras, todos los sectores de la sociedad y la población, el reforzamiento y la aplicación de la legislación sanitaria son fundamentales para lograr el control de esta enfermedad. Cada país debe desarrollar su propia estrategia para la prevención, basada en un plan de control del vector con la participación de toda la comunidad.

La vigilancia clínica y epidemiológica con apoyo del laboratorio y la supervisión entomológica, que abarca el estudio de la resistencia del vector a insecticidas, deben ser los pilares principales de esa estrategia. El propósito de la vigilancia es detectar tempranamente la introducción del virus en el país o el aumento de su circulación para poner en marcha rápidamente las medidas de control necesarias.

\section{Conclusiones}

El dengue es una enfermedad vectorial clasificada como desatendida que representa un flagelo mundial, ya que afecta a millones de personas especialmente los más pobres del planeta. Debido al cambio climático y la globalización esta enfermedad está emergiendo y evolucionando, extendiéndose a muchas regiones no endémicas, convirtiéndose en una preocupación mundial, requiriendo mejorar los esfuerzos de coor- dinación públicos y privados para abordar esta enfermedad desde una perspectiva multidisciplinaria, incluyendo los factores clínicos, ambientales y sociales.

El dengue es un problema creciente de salud pública, que afecta a más de un centenar de países en el mundo, con millones de casos informados cada año. Los cuatro tipos de dengue, están circulando en América, donde los casos aumentaron en los últimos años en forma explosiva. Los factores que han llevado a la emergencia de esta enfermedad son principalmente el cambio climático, que ha modificado el nicho ecológico de los mosquitos de la familia Aedes.

Por otro lado, el urbanismo, la falta de control del vector, las fallas en infraestructura básica y el pobre saneamiento ambiental. La intervención primaria de salud pública ha ido por la línea del uso de insecticidas para el control del vector y la detección temprana de casos. No existe aún una vacuna efectiva, sin embargo, actualmente se están realizando esfuerzos en esta materia.

El espectro clínico del dengue es muy amplio, se presenta con cefalea, dolor retro-ocular, osteomialgias, náuseas, odinofagia, vómito, debilidad y exantema. Este cuadro clínico pudiera estar acompañado de diarrea y síntomas respiratorios. Esto hace difícil diferenciar clínicamente el dengue de otras entidades que se presentan tempranamente, la notable dificultad para identificar los casos de dengue en las primeras horas de enfermedad, podría explicarse tanto por la presentación clínica inespecífica, como por los problemas atribuibles al proceso de notificación. Es importante encontrar síntomas, signos o hallazgos de laboratorio que permitan mejorar el diagnóstico clínico del dengue y establecer reglas de decisión clínica para su identificación y manejo, especialmente en el periodo temprano de la enfermedad cuando las pruebas serológicas son poco sensibles. 


\section{Bibliografía}

Duane-Gubler. (1992). Prevención del Dengue. Bullettn oftk Pan Ameman Hazlth Organization, 113(2), 109 - 120.

Guzmán-García. (2006). El dengue y el dengue hemorrágico: prioridades de investigación. Revista Panamericana de Salud Pública, 19(3), 204 - 215.

Heredia, V. (28 de Febrero de 2019). Enfrentar posibles brotes de dengue, reto en la región, según la OPS; Ecuador registró menos casos. Obtenido de El Comercio: https://www.elcomercio.com

Kantor, I. (2016). DENGUE, ZIKA Y CHIKUNGUNYA. MEDICINA (Buenos Aires) 2016; 76, 76(2), 1 - 5.

Londoño-Ocampo. (2014). Caracterización de pacientes con dengue y evaluación de biomarcadores de morbimortalidad en un centro de nivel III de Cali. Revista Colombiana Salud Libre. 2014; 9 (1): 15-20, 9(1), $15-20$
Martínez-Díaz. (Septiembre 2006). Dificultad para el diagnóstico clínico temprano del dengue en un área endémica y su impacto sobre el manejo médico inicial. Revista Médica de Chile., 134(9), 1153 - 1160.

Masciadri, V. (Enero 2019). Panorama sobre el dengue en los Estados miembros del Mercosur (19912015). Revista Panamericana de Salud Pública., 43(11)

Periago-Guzmán. (2007). Dengue y dengue hemorrágico en las Américas. Revista Panamericana de Salud Pública, 21(4), 187 - 191.

Restrepo-Arboleda. (2004). Estudio seroepidemiológico de dengue en la región del Arabá, Colombia. Infectio, 8(4), 255 - 262.

Venegas-Rivera. (2012). Dengue una enfermedad emergente y re-emergente en América. Avances en Ciencias Veterinarias, 27(2), 20 - 27.

\section{CITAR ESTE ARTICULO:}

Contreras Cano, K., Boada Rodríguez , K., Jarrin Torres, J., \& Albán Espinoza, C. (2020). Morbimortalidad del dengue grave. RECIMUNDO, 4(1), 183-191. doi:10.26820/recimundo/4.(1).enero.2020.183-191 